\title{
Review Paper on Design and Development of Metal Bending Machine
}

\author{
A. D.Zope, R.R.Deshmukh, D.R.Mete, V.S.Mane \\ (Department of Mechanical Engineering, Modern Education Society's College of Engineering/ \\ $S P P U$, India)
}

\begin{abstract}
Bending machine is used to bend a metal sheet,plate and pipe. The aim of this project is to develop a portable metal bending machine. This machine is used to bend sheets into curve and the other curvature shapes. The size of machine is very small as compare to other machines. And it is convenient for portable work. It is fully made by MS. And it is theeasy to be carry and use at any time and any place. It eases human effort and no required skill workers to operate the machine. We are developing manually operated metal bending machine with use of metal shaft, hydraulic bottle jack, pedestal bearing and support (frame). This machine works on simple kinematic system instead of complicated design. This machine can bend up-to $8 \mathrm{~mm}$ thick sheet and up-to $2 \mathrm{~cm}$ diameter of pipe. Due to its light weight and it is portable so it can be used by small workshop, fabrication shop, small scale industry etc. Bending machine is a common machine in machine shop that is used to bend a metal. There is no proper small scale bending machine for bending a pipe. A Metal Bending machine uses roller to bend metal. There are 3 roller used in bending machine. The common product of metal bending machine are pipe (square and circular) bending if separate attachment of die is provided, sheet bending. During the roll bending process the sheet or plate or pipe is passed through consecutive rollers that gradually apply pressure on pipe. Because of this pressure the change in radius of pipe or sheet occurs.
\end{abstract}

Keywords -3 roll bending, sheet and pipe bending, bending with hydraulic jack, manually bending machine

\section{INTRODUCTION}

Due to increasing globalization, it is very much essential for the manufacturer to produce a goods having highest reliability. Metal Bending and Rolling is generally used in fabrication as an alternative method for casting or forging operations. Since it is related to human being hence it is necessary to design the joint with prior attention to safely of its user. Generally Bending is a process that producesU-shape, V-shape, or channel shapes in ductile materials, most commonly in sheet metal as per requirement on different types of bending machines. Senthil Raja[2]As we have studied bending is also called as flexure which characterises the behaviour of structural element when subjected to external load applied perpendicularly to a longitudinal axis of the element. A beam is an element whose length thickness and width is smaller than the length.A shell is a geometric structure in which width and length are of same magnitude and the thickness of this geometric structureis smaller. There are two different machines available in market for bending of sheet and bending of pipe.There is no single machine available which bends sheet as well as pipe in a single unit. Roller bending process can be used to deform a sheet or plate. Cylindrical shells are the basic components used for the various engineering applications like boiler chambers, cylindrical tanks, heat exchanger shells, pressure vessels, etc. The process can be performed using many materials such as carbon and alloy steels, aluminum alloys and titanium alloys. Rolling machines with both three rollers are used to produce of cylinders with various curvatures. The rolling process is generally performed by a three roll bending machine often called as pyramid type, because of these types of arrangement of the three rollers. The process mainly consist 3 steps:

1) Positioning of the sheet or pipe.

2) Lowering of central roller.

3) Repeating feed of sheet or pipe.

In first step, a flat blank sheet is fed into the machine by two rotating side rollers until the sheet is properly positioned. In the 2 nd step, center roller is displaced downward causes bending of the sheet. In the final step, two side rollers rotate again, so that the sheet is bending continuously. 
The rolling process always starts with the crucial operation of pre-bending both ends of the sheet. The success of 3 roller bending process is depends on the experience and skill of the operator.

\subsection{Literature Review:}

The paper deals with manufacturing of pipes which use power operated sheet bending machine and manually operated sheet bending machine. It also includes limitations of manually operated bending machine. From the results of the paper the productivity of power operated bending machine is higher.P. S. Thakare[1].Author told in recent year's pipe bending machine is used in both industry and domestic purpose for bending the pipe under the required angles and dimensions. Sometimes Heat treatment is used for pipe bending but the heat treatment technique is not safe and have problems are produced in the pipes, such as wrinkling, curve forming, reduced thickness, whole forming, reduced strength, easy breakable. In the hydraulic pipe bending machine having an good advantage compared to heat treatment methods.V. Senthil Raja[2]. In this paper, a bicycle integrated pipe bending mechanism has been designed and developed. The applications of bent pipes are in frames, barricades, handle of bicycle. Most of industries uses bent pipes as air conditioning,boiler, power generation, ship building, furniture, railroad, automotive, off-road and farm equipment, aircraft etc. Due to adequate human power in countries like India, the human powered machine will result in improvement of the economy and employment of nation.In Asian countries people are facing electricity cut-off during most of the days so such system plays an important role in rural areas.H. A. Hussain[3]. Hydraulic equipment has wide use in various automobile fields. These hydraulic instruments are used for lowering and raising chair in Barber shops and in dental clinics.Hydraulic bending machine is the suitable equipmentto bend pipes, rods and bars. The pipe or rod to be bending is kept between the rollers. With use of hydraulic jack we implement force on the pipe and bend it to the required angle depending on the dies used. Hydraulic bending machine is less expensive,flexible and portable compared to those which are discussed earlier. Hence it is better to replace current standard machines by hydraulic pipe bending machine.Mohan Krishna S. A.[4]. The aim of this paper is to develop a pipe bending machine which is useful to bend a pipe in workshop. This project is to design and construct a portable pipe bending machine. This machine is used to bend steel pipes into curve and the other curvature shapes. The size of machine is very convenient for portable work. It is fully made by steel. Moreover it is easy to be carry and use at any time and any place. It decreases human effort and requires low skill labors for operating the machine. In this paper they designed manually operated pipe bending machine with use of gears, motors,pulley, and frame. This bending machine is both manually and power operated.Prashant $\mathbf{P}$. Khandare[5]. Metal forming is a process in which the desired shape and size are obtained through plastic deformation of a material without any loss of material. Bending is a metal forming process in which straight length is transformed into a curved length. Roller forming process is a continuous bending operation in which a long strip of metal is passed through typical roller adjustments, until the desired curvature shape is obtained. The bending changes according to material and according to the loading condition and thickness of sheet.Mahesh Gadekar [6]

\section{Block Diagram:}

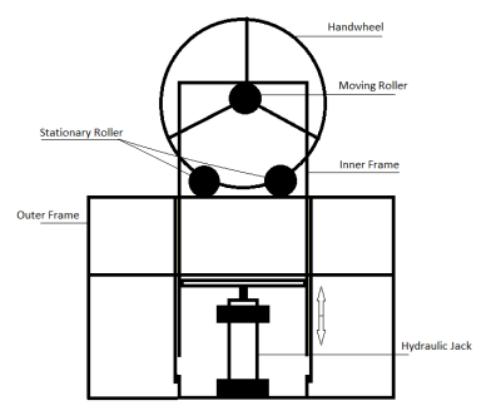

Fig.(1): Block diagram of metal bending machine 


\section{Components used:}

1.Hydraulic Jack:

To lift heavy loads, hydraulic jack is used. We use the hydraulic bottle jack to lift the inner frame. Mohan Krishna S A[4].

2. Stationary Rollers:

These rollers are on the outer frame of the bender, they are used to give support to sheet and pipes.

3. Moving Roller:

This roller is on the inner frame of the bender, it is used to move the sheet in continuous motion which is further used to bend the sheet or pipe with the help of axis wheel and pneumatic jack.The roller shaft is directly connected to handwheel shaft.

4. Hand wheel:

It is nothing but a rotary wheel of round pipe to give rolling action to rollers manually. When we rotate the wheel, a torque is applied on it to pass the sheet and pipes under it.

\section{WORKING:}

We are going to design and develop metal bending machine i.e. a sheet and pipe roller with the help of a hydraulic bottle jack and rollers as shown in fig.(1). It consist three rollers.One roller is at the upper frame and another two rollers are at the lower frame, and with the help of bottle jack force we will bend the metals. It has 2 MS square pipe frames one is fixed horizontally and one is vertically. At horizontal frame consist pedestal bearing through which shaft or roller is rotates easily. At horizontal frame have two rollers at parallel. And at vertical frame carries also one pedestal bearing and one roller through it. Hydraulic bottle jack is used to give motion to vertical frame by which we can apply gradual load while bending. Sheet is feed from these rollers, because of handlemovement; this sheet is passed from rollers by rolling motion. We have to rotate handle by manually which is attached at roller of vertical frame.

\section{Scope:}

- To bend metal sheet and pipe in one system.

- To operate the system hydraulically.

- To ease the operation in small scale industries.

\section{References}

[1] P. S. Thakare, P. G. Mehar, Dr. A. V. Vanalkar and Dr. C. C. Handa, "Productivity Analysis of Manually Operated And Power Operated Sheet Bending Machine: A Comparative Study", International Journal of Engineering Research and Applications (IJERA), ISSN: 2248-9622, Vol. 2, Issue 2, Mar-Apr 2012, PP.111-114.

[2] V. Senthil Raja, R.Maguteeswaran, C. Karthik, S.Rajarajan and D. Shanmuga Vadivel, "A New Model in Design and Manufacturing of Mobile Hydraulic Pipe Bending Machine in Industry", International Journal of Engineering Research \& Technology (IJERT), ISSN: 2278-0181, Vol. 3 Issue 1, January - 2014 PP 2706-2713.

[3] H. A. Hussain, M. Sohail Pervez, Md. Naushad Alam and Atul. P. Ganorkar, "Design and Development of Bicycle Integrated Pipe Bending Machine", IOSR Journal of Mechanical and Civil Engineering (IOSR-JMCE), e-ISSN: 2278-1684, p-ISSN: 2320-334X, 2014, PP 24-28.

[4] Mohan Krishna S. A., "Experimental Design and Fabrication of a Portable Hydraulic Pipe Bending Machine", International Journal of Development Research, ISSN: 2230-9926, Vol. 4, Issue, 12, pp. 2681-2684, December, 2014, PP 2681-2684.

[5] Prashant P. Khandare, Dhiral N. Patel, Mayur K. Aher, Ravi S. Parbat and Prof. Swapnil S. Patil, "Study of Portable 3 Roller Pipe Bending Machine", International Conference on Emerging Trends in Engineering and Management Research, ISBN 978-81932074-7-5, 23 March 2016, 624-630.

[6] Mahesh Gadekar and Mr. Amol, "Design \& Development of Three Roller Sheet Bending Machine", International Journal on Recent and Innovation Trends in Computing and Communication, ISSN: 2321-8169, Volume: 3, Issue: 8, August 2015, PP 5132 5135 . 